\section{Metabolic Syndrome and its Risk Factors among Overweight and Obese Palestinian Schoolchildren using IDF and NCEP-ATP/III Definitions}

\section{Abstract}

Background: Warning signs of metabolic syndrome (MetS) can appear during childhood. Early detection and treatment of MetS is likely to reduce morbidity and mortality in adulthood and help to keep to minimum the global burden of cardiovascular diseases and type II diabetes. This study aimed to establish the prevalence and to characterize metabolic syndrome and its individual components among overweight and obese Palestinian schoolchildren aged $6-<18$ years in the West Bank.

Methods: A cross sectional study was conducted in the West Bank-Palestine in the year 2014. Out of the 840 schoolchildren, 216 (30.7\%) were overweight and obese; 146 of them were evaluated for MetS using the International Diabetes Federation and modified National Cholesterol Education Program-Third Adult Treatment Panel definitions.

Results: Using NCEP criteria, MetS was significantly more prevalent in overweight and obese children $(23.3 \%)$ than IDF $(15.8 \%)$ and among boys $(22.2 \%$ for NCEP vs $12.3 \%$ for IDF) and girls (23.3\% for NCEP vs $20.0 \%$ for IDF). No sex-specific differences in the prevalence of MetS between age groups were determined using both criteria. The prevalence of individual MetS components according the IDF and NCEP criteria were respectively; (32\% and $25.3 \%$ ) for increased waist circumference, $(15.8 \%$ and $37.0 \%)$ for increased blood pressure, $(9.7 \%$ and $24.8 \%)$ for increased triglyceride, $(57.2 \%$ and $55.9 \%)$ for low HDL, and $(39.7 \%$ and $15.8 \%$ ) for increased fast blood sugar. Clustering of metabolic abnormalities had significantly increased by increasing body mass index and waist circumferences, and with decreased $\mathrm{HDL}$ and elevated triglyceride.

Conclusions: The prevalence of MetS among overweight and obese Palestinian schoolchildren is high with dyslipidemia being the most common MetS abnormality. Regardless the definition used to diagnose MetS among children; the findings of this study present a serious threat to current and future health of Palestinian children.

Keywords: Dyslipidemia; Metabolic syndrome; Obesity; Cardiovascular disease; Palestine

\section{Basma Damiri1", Amjad Abu Alhala², Lana Najjar ${ }^{2}$ and Saleh Alqadome ${ }^{2}$}

1 Medicine and Health Science Faculty, Drug and Toxicology Division, An-Najah National University, Nablus, Palestine

2 Department of Medicine, An-Najah National University, Nablus, Palestine

*Corresponding author:

Basma Damiri

” bdamiri@najah.edu

Medicine and Health Science Faculty, Drug and Toxicology Division, An-Najah National University, Nablus, 0970, Palestine.

Tel: 00970592234270

Citation: Damiri B, Alhala AA, Najjar L, Alqadome S (2018) Metabolic Syndrome and its Risk Factors among Overweight and Obese Palestinian Schoolchildren using IDF and NCEP-ATP/III Definitions. Ann Clin Lab Res Vol.6 No.3: 242

\section{Introduction}

Metabolic syndrome (MetS) is characterized by a cluster of several metabolic and cardiovascular risk factors such as abdominal obesity, insulin resistance, atherogenic dyslipidemia, and hypertension [1-3]. It was first considered to be a condition of adulthood and linked to cardiovascular morbidity and mortality [4]. More recently, it has been identified as a condition of childhood [4,5]. The risk of having metabolic syndrome increases with age, affecting less than $10 \%$ of people in their 20 's and $40 \%$ 
of people in their 60's. However, warning signs of metabolic syndrome can appear during childhood [3]. Early detection and treatment of MetS is likely to reduce morbidity and mortality in adulthood and help to keep to minimum the global burden of CVD and type II diabetes.

Childhood obesity is a significant health problem and associated with several metabolic and cardiovascular complications [68]. Overweight and obesity had reached alarming rate among Palestinians [9-11]. Importantly, overweight and obesity, as well as their related diseases, are largely preventable. Prevention of childhood obesity, therefore, needs high priority. A comprehensive understanding of MetS in overweight and obese children and adolescent population may be important for the specific direction of prevention strategies. To the author's best knowledge, no studies had been conducted in Palestine to establish the prevalence of MetS among children while few studies have indicated high prevalence of MetS among adults [12-14] and among obese and overweight adults [11,15].

To date, no uniform definition has been established to diagnose MetS among children and more studies are recommended for each ethnicity. Currently, the two most widely used definitions are those of the National Cholesterol Education Program Adult Treatment Panel III (NCEP-ATP/III) and the International Diabetes Federation (IDF) [16-21]. Sine a formal definition has not been developed for Palestinians, this study aimed to characterize and establish prevalence of MetS and its components using IDF and NCEP-ATP/III definitions among overweight and obese schoolchildren in Nablus-Palestine and to explore its possible risk factors.

\section{Materials and Methods}

\section{Study population and sampling technique}

A school-based cross-sectional study was conducted in 2014 in Nablus Districts in Palestine. A multi-stage stratified proportional sampling method was used to select the subjects form 39231 students. To diagnose MetS according to the new IDF definition, age is divided into three groups: 6 years to $<10$ years; age 10 years to $<16$ years; and 16 years to $<18$ years old. In the first stage, 840 participants ( 420 boys and 420 girls) were randomly selected from 12 schools. The number of participants had been selected then proportionally from each age group: $6-<10$ years (320; 160 boys and 160 girls), 10-<16years (440; 220 boys and 220 girls), 16-<18years (160; 80 boys and 80 girls). In the second stage, children who presented with overweight and obesity and had met the inclusion criteria were invited to have blood samples taken (no.=216). The child was excluded from the study if he/she had hypo- or hyper-thyroidism, Cushing syndrome, epileptic, or taking regular medications other than anti-diabetic or lipidemic medication as indicated by his parents, and who had participated in the pilot study or his parents refused to sign informed consent.

\section{Diagnostic criteria}

The MetS prevalence was determined by the IDF new criteria for children and the NCEP-ATP III criteria adapted for youth [19,22,23]. For children aged between 6 and $<10$ years: Abdominal obesity is required as essential criteria. It is defined as waist circumference
(WC) $\geq 90^{\text {th }}$ percentile for age and gender; using the cut-off points established for American children and adolescents [24] but the MetS can't be diagnosed as stated in the IDF definition $[19,25]$. European data for WC was used as recommended by IDF criteria as no specific ethnicity cut-off points are available for Palestinian $[19,25]$. For children aged between 10 and $<16$ years, a diagnosis of the metabolic syndrome made as the presence of abdominal obesity (WC $\geq 90^{\text {th }}$ percentile or adult cut-off if lower) and the presence of two or more of the other components: Elevated TG $(\geq 1.7 \mathrm{mmol} / \mathrm{L}(\geq 150 \mathrm{mg} / \mathrm{dL})$ ), low $\mathrm{HDL}$ cholesterol $(<1.03 \mathrm{mmol} / \mathrm{L}(<40 \mathrm{mg} / \mathrm{dL}))$, high blood pressure (Systolic $\geq 130$ $\mathrm{mmHg}$ or diastolic $\geq 85 \mathrm{mmHg}$ ), and elevated blood glucose ( $\geq$ $5.6 \mathrm{mmol} / \mathrm{L}$ ( $\geq 100 \mathrm{mg} / \mathrm{dL}$ ) $[19,25]$. For children aged 16 years or more, the IDF criteria for adults is used to define it; central obesity (defined as WC $\geq 94 \mathrm{~cm}$ for men and $\geq 80 \mathrm{~cm}$ for women) plus any two of the following four factors: Raised triglycerides: $\geq$ $1.7 \mathrm{mmol} / \mathrm{L}$, reduced HDL-cholesterol: $<1.03 \mathrm{mmol} / \mathrm{L}(<40 \mathrm{mg} / \mathrm{dL})$ in males and $<1.29 \mathrm{mmol} / \mathrm{L}(<50 \mathrm{mg} / \mathrm{dL}$ ) in females, or specific treatment for these lipid abnormalities, raised blood pressure: systolic BP $\geq 130$ or diastolic BP $\geq 85 \mathrm{~mm} \mathrm{Hg}$, or treatment of previously diagnosed hypertension, impaired fasting glycaemia (IFG): Fasting plasma glucose (FPG) $\geq 5.6 \mathrm{mmol} / \mathrm{L}$ ( $\geq 100 \mathrm{mg} / \mathrm{dL}$ ), or previously diagnosed type II diabetes. To diagnose MetS using modified NCEP-ATP III criteria, the definition based on Cook et al., (2003) work [17] and was altered by Wan et al., (2007) [23]. This definition is based on criteria analogous to that of the National Cholesterol Education Program Expert Panel on Detection, Evaluation and Treatment of High Blood Cholesterol in Adult Treatment Panel III [26]. It defines MetS as three or more of the following: fasting TG $\geq 110 \mathrm{mg} / \mathrm{dL}$; HDL cholesterol $<40 \mathrm{mg} / \mathrm{dL}$; WC $\geq 90^{\text {th }}$ percentile for age and sex, according to national reference curves [27]; systolic blood pressure (SBP) and/or diastolic blood pressure $(D B P) \geq 90^{\text {th }}$ percentile for sex, age and height, from national reference cut-off points [17]; FBG $\geq 100 \mathrm{mg} / \mathrm{dL}$ [23]. Obesity was determined based on BMI and the classification scheme introduced by the Centers for Disease Control and prevention $(C D C)$. $C D C$ charts were used for defining respondents who were at risk of overweight (BMI > 85th percentile) and obesity (BMI $>95^{\text {th }}$ percentile) $[28,29]$. Abdominal obesity was defined using WC percentiles by sex and age. Percentiles $\geq 90$ were defined as abdominal obesity. Hypertension was detected using seventh Joint National Committee on Evaluation, Diagnosis, Treatment, and Prevention of Blood Pressure (JNC7) classification criteria. If blood pressure (systolic and diastolic) reading was at $>90^{\text {th }}$ percentile based on sex and height, it was defined as pre-hypertension and readings $>95$ and $>99$ were defined as type I and II hypertension, respectively [30,31]. The health status of children was established from the self -administrated questionnaire that was answered by the parents. The parents were also asked about the type of medication that is given to their children to treat diabetes if found. Anthropometrics, blood pressure measurements, and biochemical analysis were done as described previously $[11,15]$.

\section{Data analysis}

The Statistical Product and Service Solutions (SPSS) (version 21, IBM Corporation) was used for data analysis. Means, standard deviations, and percentages wherever appropriate were used to 
describe variables and the Pearson Chi-square and Fisher Exact test were used to compare the categorical variables. A p-value of less than or equal 0.05 was considered statistically significant.

\section{Result}

Stage 1: Out of the 840 children, $216(30.7 \%)$ were overweight and obese ( $14.2 \%$ overweight and $16.5 \%$ obese) with significant increase in the prevalence of obesity and overweight among age group $10-<18$ compared to age group $6-<10$ years ( $p$ value $<0.01$ ) (Additional File 1). Sex-specific anthropometric measurements were established for boys and girls and are shown in Additional File 2.

Stage 2: Out of 216 overweight and obese children, 146 participants ( 81 boys and 65 girls) underwent the second stage of this study and 70 participants refused to be tested for blood. Of the 146 agreed to participate in stage $2,71.2 \%$ were obese ( $41 \%$ girls, $59 \%$ boys) and $28.8 \%$ were overweight ( $51 \%$ girls, $49 \%$ boys).

\section{Prevalence of MetS based on the criteria used, gender, and age group}

Based on the criteria used, the prevalence of MetS was high and significantly more prevalent using NCEP (23.3\%) than IDF criteria $(15.8 \%)$ ( $p$ value 0.000 ) (Table 1 ). Based on gender, no sexspecific differences in the prevalence of MetS between boys and girls were determined using IDF ( $p$ value 0.21 ) or NCEP criteria ( $p$ value 0.734 ) (Table 1). Based on age groups, no significant difference in the prevalence of MetS was determined between the age group $6-<10$ years and the age group $10-<18$ years using IDF ( $p$ value 0.332 ) and NCEP criteria ( $p$ value 0.995 ) (Table 2 ).

\section{Differences in the prevalence of MetS abnormalities based on the diagnostic criteria used}

The most prevalent component of MetS was reduced HDL according to both criteria (Table 3). The prevalence of individual
MetS components according the IDF and NCEP criteria were respectively; (32.2\% and $25.3 \%$ ) for increased WC, $(15.8 \%$ and $37.0 \%$ ) for elevated blood pressure, (9.7\% and $24.8 \%$ ) for elevated triglyceride, (57.2\% and 55.9\%) for reduced HDL and (39.7\% and $15.8 \%$ ) for elevated FBS (Table 3 ). Increased WC, reduced $\mathrm{HDL}$, and elevated FBS were significantly more prevalent according to IDF (32.2 and 57.2\%, 39.7\%; respectively) than NCEP (25.3\% and 55.9\%, 15.8\%; respectively) ( $p$ value 0.000 ). On the other hand, elevated triglyceride and elevated blood pressure were significantly more prevalent according to NCEP $(24.8 \%$ and $37.0 \%$; respectively) than IDF ( $9.7 \%$ and $15.8 \%$; respectively) ( $p$ value 0.000$)$.

\section{Risk factors and culturing of metabolic abnormalities}

Age: The prevalence of the following abnormalities had significantly increased with increasing age: overweight and obesity ( $p$ value 0.001), increased central obesity using NCEP definition ( $p$ value 0.038 ), elevated BP using IDF definition ( $p$ value 0.031 ), and elevated triglyceride using IDF definition ( $p$ value 0.041) (Table 4).

Gender: Sex-specific clustering of MetS abnormalities had shown no significant differences between boys and girls using both IDF ( $p$ value 0.453 ) and NCEP criteria ( $p$ value 0.489 ) (Additional File 3). Sex-specific frequency of individual components of the MetS among overweight and obese children is shown in Table 5. According to IDF criteria, central obesity (WC) and FBS were significantly more prevalent in girls $(43.1 \%$ and $49.2 \%$; respectively) than boys ( $23.5 \%$ and $32.1 \%$; respectively) ( $p$ value 0.012 and 0.036; receptively) (Table 5).

BMI: With increasing BMI, clustering of metabolic abnormalities had significantly increased according to IDF and NCEP criteria (Additional File 3). This includes central obesity according to both criteria ( $p$ value 0.000 ), BP according to NCEP criteria ( $p$ value 0.013 ), and reduced HDL according to both criteria ( $p$ value $\leq 0.001$ ) (Additional File

Table 1 Sex-specific prevalence of MetS according to IDF and NCEP criteria ( $N=146)$.

\begin{tabular}{|c|c|c|c|c|c|}
\hline \multirow[t]{2}{*}{ MetS } & $\begin{array}{c}\text { Boys } \\
\text { (no.=81) }\end{array}$ & $\begin{array}{c}\text { Girls } \\
\text { (no. 65) }\end{array}$ & $\begin{array}{c}\text { Total } \\
\text { (no. 146) }\end{array}$ & \multirow[t]{2}{*}{ p-value } & \multirow[t]{2}{*}{ OR ( $95 \% \mathrm{Cl})$} \\
\hline & no. (\%) & no. (\%) & no. (\%) & & \\
\hline IDF overweight and obese & $10(12.3)$ & $13(20.0)$ & $23(15.8)$ & 0.21 & $1.77(0.23-4.36)$ \\
\hline IDF overweight & $0(0)$ & $1(4.8)$ & $1(2.4)$ & \multirow{2}{*}{0.19} & \multirow{2}{*}{$1.05(0.954-1.115)$} \\
\hline IDF obese & $10(16.7)$ & $12(27.3)$ & $22(21.2)$ & & \\
\hline NCEP overweight and obese & $18(22.2)$ & $16(24.6)$ & $34(23.3)$ & 0.734 & $1.143(0.529-2.468)$ \\
\hline NCEP overweight & $0(0)$ & $0(0)$ & $0(0)$ & \multirow{2}{*}{0.494} & \multirow{2}{*}{$1.33(0.584-3.045)$} \\
\hline NCEP obese & $18(30.0)$ & $16(36.4)$ & $34(32.7)$ & & \\
\hline
\end{tabular}

Table 2 Age-specific prevalence of MetS and metabolic abnormalities according to IDF and NCEP criteria.

\begin{tabular}{|c|c|c|c|c|}
\hline \multirow{2}{*}{ Age-specific prevalence } & $6-<10$ (no. $=30)$ & $10-<18$ (no. =116) & \multirow{2}{*}{ p value } & \multirow{2}{*}{ OR ( 95\%Cl) } \\
\hline & no. (\%) & no. (\%) & & \\
\hline Met NCEP & $7(23.3)$ & $27(23.3)$ & 0.995 & $0.997(0.39-2.57)$ \\
\hline Met IDF & $3(10)$ & $20(17.2)$ & 0.332 & $1.875(0.52-6.79)$ \\
\hline Met NCEP vs IDF $(10-<18)$ & \multicolumn{2}{|c|}{--} & $0.000 *$ & 48.73(12.12-195.9) \\
\hline Met IDF obese vs overweight $(10-<18)$ & \multicolumn{2}{|c|}{--} & $0.001^{*}$ & $14.16(1.82-110.15)$ \\
\hline Met NCEP obese vs overweight $(10-<18)$ & \multicolumn{2}{|c|}{-- } & $0.000^{*}$ & $1.57(1.33-1.87)$ \\
\hline
\end{tabular}


Table 3 Prevalence of MetS abnormalities according to IDF and NCEP criteria.

\begin{tabular}{|c|c|c|c|}
\hline \multirow{2}{*}{ Variable } & IDF & NCEP & \multirow{2}{*}{$p$ value } \\
\cline { 2 - 4 } & no. (\%) & no. (\%) & $0.000^{*}$ \\
\hline WC & $47(32.2)$ & $37(25.3)$ & $0.000^{*}$ \\
\hline BP & $23(15.8)$ & $54(37.0)$ & $0.000^{*}$ \\
\hline Triglyceride & $14(9.7)$ & $36(24.8)$ & $0.000^{*}$ \\
\hline HDL & $83(57.2)$ & $81(55.9)$ & $0.000^{*}$ \\
\hline FBS & $58(39.7)$ & $23(15.8)$ & \\
\hline
\end{tabular}

Table 4 Age-specific prevalence of metabolic abnormalities according to IDF and NCEP criteria.

\begin{tabular}{|c|c|c|c|c|}
\hline \multirow{2}{*}{ Variable } & $6-<10$ (no. $=30$ ) & $10-<18$ (no. =116) & \multirow{2}{*}{$p$ value } & \multirow{2}{*}{ OR ( $95 \% \mathrm{Cl})$} \\
\hline & no. (\%) & no. (\%) & & \\
\hline BMI (Overweight) & $0(0)$ & $42(36.2)$ & -- & -- \\
\hline BMI(Obese) & $30(100)$ & $74(63.8)$ & -- & -- \\
\hline BMI (Total overweight and obese) & $30(100)$ & $116(100)$ & $0.000 *$ & $1.568(1.37-1.80)$ \\
\hline WCIDF & $12(40)$ & $35(30.2)$ & 0.304 & $0.648(0.28-1.49)$ \\
\hline WC NCEP & $12(40)$ & $25(21.6)$ & $0.038 *$ & $0.412(0.175-0.986)$ \\
\hline BP IDF & $1(3.3)$ & 22(19) & $0.031^{*}$ & $6.787(0.88-52.55)$ \\
\hline BP NCEP & $15(50)$ & $39(33.6)$ & 0.098 & $0.506(0.23-1.14)$ \\
\hline Triglyceride IDF & $0(0)$ & $15(21.9)$ & $0.041^{*}$ & $1.149(1.071-1.232)$ \\
\hline Triglyceride NCEP & $4(13.3)$ & $33(28.4)$ & 0.09 & $2.584(0.84-7.98)$ \\
\hline HDL IDF & $15(50)$ & $69(59.6)$ & 0.349 & $1.468(0.656-3.287)$ \\
\hline HDL NCEP & $15(50)$ & $67(57.8)$ & 0.445 & $1.367(0.61-3.06)$ \\
\hline FBS IDF & $10(33.3)$ & $48(41.4)$ & 0.422 & $1.412(0.61-3.28)$ \\
\hline FBS NCEP & $3(10)$ & $20(17.2)$ & 0.332 & $1.875(0.518-6.787)$ \\
\hline
\end{tabular}

Table 5 Sex-specific frequency of individual components of the MetS among overweight and obese children.

\begin{tabular}{|c|c|c|c|c|c|}
\hline \multirow{2}{*}{ Sex-specific frequency } & Boys & Girls & Total & \multirow{2}{*}{ p value* } & OR, 95\% (CI) \\
\cline { 2 - 5 } & no. (\%) & no. (\%) & no. (\%) & & $0.802(0.482-1.335)$ \\
\hline BMI (Overweight) & $21(25.9)$ & $21(32.3)$ & $42(28.8)$ & 0.397 & $1.094(0.886-1.352)$ \\
\hline BMI(Obese) & $60(74.1)$ & $44(67.6)$ & $104(71.2)$ & 0.405 & $0.733(.037-1.505)$ \\
\hline BMI Total & $81(55.5)$ & $65(44.5)$ & $146(100)$ & 0.397 & $2.469(1.213-5.027)$ \\
\hline WC IDF & $19(23.5)$ & $28(43.1)$ & $47(32.2)$ & $0.012^{*}$ & $1.673(0.790-3.544)$ \\
\hline WC NCEP & $17(21.0)$ & $20(30.8)$ & $37(25.3)$ & 0.177 & $0.769(0.310-1.910)$ \\
\hline BP IDF & $14(17.3)$ & $9(13.8)$ & $23(15.8)$ & 0.571 & $1.601(0.813-3.151)$ \\
\hline BP NCEP & $26(32.1)$ & $28(43.1)$ & $54(37.0)$ & 0.172 & $1.786(0.586-5.438)$ \\
\hline Triglyceride IDF & $6(7.4)$ & $8(12.5)$ & $14(9.7)$ & 0.303 & $1.18(.0554-2.514)$ \\
\hline Triglyceride NCEP & $19(23.5)$ & $17(26.6)$ & $36(24.8)$ & 0.667 & $0.831(0.428-1.609)$ \\
\hline HDL IDF & $48(59.3)$ & $35(54.7)$ & $83(57.2)$ & 0.581 & $0.732(0.378-1.417)$ \\
\hline HDL NCEP & $48(59.3)$ & $33(51.6)$ & $81(55.9)$ & 0.732 & $2.05(1.046-4.024)$ \\
\hline FBS IDF & $26(32.1)$ & $32(49.2)$ & $58(39.7)$ & $0.036 *$ & $1.44(0.59-3.52)$ \\
\hline FBS NCEP & $11(13.6)$ & $12(18.5)$ & $23(15.8)$ & 0.647 & \\
\hline
\end{tabular}

4). MetS was significantly more prevalent in obese children than overweight children using IDF ( $p$ value 0.005 ) and NCEP criteria ( $p$ value 0.000 ) criteria (Additional File 4).

Elevated FBS: Children with elevated FBS were at higher risk of having MetS according to NCEP criteria ( $p$ value 0.000 ) but not the IDF ( $p$ value 0.24) (Table 6).

Central obesity: Children with increased central obesity had shown significant increase in clustering of metabolic abnormalities (3 or more) (Additional File 3) according to NCEP (67.6\%) ( $p$ value 0.000 ) and IDF criteria (48.9\%) ( $p$ value 0.04 ). They have shown also higher risk of having MetS according to both criteria (Table 6).

\section{Discussion}

Metabolic syndrome (MetS) is one of the major causes of morbidity and mortality in the world [32]. The clustering of cardio vascular disease (CVD) risk factors that typifies the metabolic syndrome is now considered the driving force for a CVD epidemic. It is estimated that around a quarter of the world's adult population has metabolic syndrome [33]. The importance of identifying the risk factors of MetS in children is because its presence in this phase of life remains many years in silence and therefore, its identification can contribute to the prevention of chronic diseases and premature death [16,34]. The 
Table 6 Risk factors associated with MetS (increased waist circumferences, elevated fast blood sugar, decreased high density lipoprotein, elevated blood pressure, and elevated triglyceride).

\begin{tabular}{|c|c|c|c|c|c|c|}
\hline \multirow{2}{*}{ Variable } & \multicolumn{3}{|c|}{ MetS IDF } & \multicolumn{2}{c|}{ MetS NCEP } \\
\cline { 2 - 7 } & no.(\%) & p value & OR, 95\% (CI) & no.(\%) & p value & OR, 95\%(CI) \\
\hline WC & $23(48.9)$ & $0.000^{* * *}$ & $1.96(1.48-2.54)$ & $23(67.6)$ & $0.000^{* * *}$ & $14.64(5.89-36.40)$ \\
\hline FBS & $23(15.8)$ & 0.24 & $2.79(1.12-6.98)$ & $14(60.9)$ & $0.000^{* * *}$ & $8.01(3.053-21.021)$ \\
\hline HDL & $22(95.7)$ & $0.000^{* * *}$ & $21.65(2.829-165.625)$ & $38(88.4)$ & $0.000^{* * *}$ & $10.19(3.709-28.004)$ \\
\hline BP & $12(52.2)$ & $0.000^{* * *}$ & $11.1(3.98-30.991)$ & $35(81.4)$ & $0.000^{* * *}$ & $19.34(7.74-48.31)$ \\
\hline Trig & $8(34.8)$ & $0.000^{* * *}$ & $8.83(2.804-27.860)$ & $26(60.5)$ & $0.000^{* * *}$ & $12.79(5.34-30.67)$ \\
\hline
\end{tabular}

prevalence of metabolic syndrome in children and adolescents has been reported in various populations using a variety of age and gender specific cut-off points for the different components (waist circumference, fast blood sugar, blood pressure, and lipid levels). To the authors' best knowledge, this is the first study that had established the prevalence of MetS among children and had explored its risk factors.

The findings of this study had demonstrated that the overall prevalence of MetS was high among overweight and obese children aged $6-<18$ and significantly higher according NCEP criteria $(23.3 \%)$ than IDF (15.8\%) without significant differences between age groups and genders. Similar frequencies of MetS were reported among overweight and obese children world widely [17,35-37]. Higher frequencies were reported in different populations $[38,39]$ and when IDF definition was implemented [40-44].

In order to help policy makers in establishing policies and strategies for preventing MetS among children, we had explored the MetS risk factors among children. The pathogenesis of the MetS and each of its components is complex and not well understood and continues to challenge the experts but both insulin resistance and central obesity are considered significant factors [24,27]. Obesity is associated with metabolic disorders starting early in life. Obesity, particularly in the central (abdominal) region, is associated with an increase in risk of cardiovascular disease and has been determined as a key precipitating factor for type II diabetes [45]. The finding of this study indicate that the prevalence of overweight and obesity was high (30.7\%) among Palestinian schoolchildren and the clustering of metabolic abnormalities had increased with increasing body mass index with no gender-specific differences. Obesity was associated with increased central obesity and decreased HDL according to IDF and NCEP definitions and elevated BP according to NCEP definition. The IDF groups suggest that the MetS should not be diagnosed in children younger than 10 , but that a strong message for weight reduction should be delivered for those with abdominal obesity [20]. They assume that the IDF criteria for MetS in children and adolescent may change in future as more outcome data become available. Therefore, we had established the prevalence of MetS in children aged $10-<18$ years which was significantly more pronounced when modified NCEP definition was implemented than IDF definition and had increased with increasing obesity according to both criteria. None of the overweight children aged $10-<18$ years had been diagnosed with MetS according to NCEP definition and only one had been diagnosed with MetS according to IDF definition. These results indicate that obesity but not gender or age could be significant risk factors for increased MetS among Palestinian schoolchildren. Overweight and obesity, as well as their related diseases, are largely preventable. Prevention of childhood obesity among Palestinian children, therefore, needs high priority. Depending on these results, we assume also that both definitions with their cutoffs used may be not realistic for diagnosing MetS in normal weight Palestinian school children.

Most research focus on investigation of how obesity in children should be better defined (e.g. WC, BMI, weight, etc.) and develops ethnic specific age and sex normal ranges for WC, ideally based on healthy values [25]. Central obesity is a prerequisite risk factor for the diagnosis of the syndrome in the new IDF definition [45]. Therefore, we had investigated the association between central obesity and FBS with other risk factors. Children in this study had shown significant increase in the prevalence of central obesity according to IDF (32.2\%) compared to NCEP (25.3\%) definitions and the prevalence had increased with increasing BMI. Children with increased central obesity had shown significant increase in clustering of metabolic abnormalities (3 or more) according to NCEP (67.6\%) compared to IDF definition (48.9\%). Therefore, central obesity had significantly increased the risk of having Mets according to NCEP definition. Surprisingly, central obesity was not associated with increased FBS according to both definitions. Although elevated FBS was the second prominent component using IDF definition, it was not associated with any MetS abnormalities.

Gender is another risk factor. Different studies have been undertaken to characterize the major components of the metabolic syndrome in females and males in different populations [19,28,46-49]. In agreement with other studies among Palestinians, MetS and its other risk factors were more clustered in girls than boys with no significant differences using both definitions [11,13-15,50] and increased with increasing obesity $[11,15]$. Elevated FBS and central obesity were significantly more prevalent in girls than boys using IDF definition. Moreover, these risk factors seem to cluster at early age in girls as $28.6 \%$ of girls have $\geq 3$ components in age group $6-<10$ years compared to $18.8 \%$ in boys using NCEP definition. None of the boys at this age has three of more components or had met the IDF definition. In addition to that, although no statistical differences in BMI between boys and girls in all age groups was determined, central obesity was more prevalent among girls using both definitions 
and significantly higher using IDF definition. These results agree with previous studies $[11,14,51,52]$. Therefore, more attention should be paid to obese girls especially those with central obesity and elevated levels of fast blood sugar as they are at higher risk for early mortality.

The prevalence of suggested risk factors that contribute to the MetS in children varies significantly with the cut off used [53]. Insufficient data about waist circumferences cut-off points have prevented region-specific definitions to be established for the Arabian population. The presence of central obesity is an absolute requirement for the IDF criteria but the European threshold to define central obesity in our population may be under-inclusive for our population (ethnicity). More data is needed in this subject to establish Palestinian waist circumferences thresholds. This could be one of the reasons for having higher prevalence of MetS in this study according to NCEP definition than the IDF definition. In fact, the prevalence of MetS for Palestinians from the same district was more using IDF definition than NCEP definition for overweight and obese adults $[11,15]$. Moreover, different studies had indicated that MetS is significantly more prevalent among adult Palestinians when IDF definition is implemented than NCEP definition $[14,51,52]$. Therefore, similar to other studies $[54,55]$, the results of this study indicate that modified NCEPATP/III definition with modified cut-off points for youth should be considered for the diagnosis of the MetS among Palestinian children unless waist circumference with ethnicity specific values for Palestinians are established. In this study, the prevalence of MetS abnormalities varied between IDF and NCEP definitions. The most prevalent component of MetS among study subjects was reduced HDL-cholesterol using both definitions. Reduced HDL and elevated BP were significantly associated with increased central obesity and elevated triglyceride using NCEP definition. Similar results were observed among overweight and obese adult Palestinians in both sexes $[11,15]$. Moreover, elevated triglyceride was associated significantly with all abnormalities except central obesity according to NCEP definition. Screening for dyslipidemia among children and adults is necessary especially among children at risk. We are now investigating the risk factors for reduced HDL among Palestinians in both genders and in different age groups. Overall, obesity, central obesity, and dyslipidemia could be the most significant risk factors for MetS among children in Palestine according to NCEP definition.

\section{Conclusion}

The findings of this study provide evidence-based data on the considerable prevalence of childhood MetS among Palestinian children. Obesity and central obesity as well as dyslipidemia were the most significant risk factors for MetS among children. Because the number of overweight and obese children is increasing and because it is evident that MetS starts at early life, we recommend that more attention should be paid on the young population at risk to reduce childhood obesity and subsequent cardiovascular diseases. Prevention of childhood obesity among Palestinian children needs high priority. Attention should be made through health care providers, social media, and educational campaigns about the benefits of losing weight in reducing MetS and its components. Depending on the results, we assume that both definitions, IDF and NCEP-ATP III, with their cutoffs used may be not realistic for diagnosing MetS in normal weight Palestinian children. Therefore, we recommend developing ethnic specific age and sex normal ranges for waist circumferences, ideally based on healthy values. More research is needed in order to identify optimal criteria for defining and establishing cut off for different MetS components for Palestinian at different age groups. However, modified NCEP-ATP/III definition with modified cut-off points for youth should be considered for the diagnosis of the MetS among obese Palestinian children unless waist circumferences with ethnicity specific values for Palestinians are established.

\section{Declarations}

\section{Competing of interests}

"The authors declare that they have no competing interests" in this section.

\section{Ethical considerations}

The study was carried out in accordance with the ethical standards, Declarations of Helsinki. Approval was obtained from Institutional Review Board "IRB" at An-Najah National University in Palestine prior to the research conduction. Permission from the Ministry of Education and the principal of the school was granted. All study participants were freely accepted to join the study and they provided a signed consent form from their parents. All were assured that all data collected would be confidential and available for the researcher only. It was explained to the participants that they had the right to withdraw from the research anytime. Blood tests were free and the participants did not pay for it.

\section{Consent for publication}

"Not applicable" in this section.

\section{Author's contributors}

$B D$ wrote the initial draft of the manuscript. $B D, A A H, L N$, and $S A$ contributed to the study design and literature the search, $A A H$, $\mathrm{LN}$, and SA carried out the data collection. BD, AAH analyzed the data and prepared data tables. All authors were involved in interrupting the data and had full approval of the submitted and published version and all authors approved the final manuscript.

\section{Availability of data and materials}

Most data generated or analysed during this study are included in this manuscript. Other data that support the findings of this study and/or analysed during the current study are available from the corresponding author on reasonable request.

\section{Acknowledgments}

We are very grateful to Ministry of Education-Nablus division and for their cooperation and help. 


\section{References}

1 Grundy SM, Cleeman JI, Merz CN, Brewer HB Jr, Clark LT, et al. (2004) Implications of recent clinical trials for the national cholesterol education program adult treatment panel III guidelines. Circulation 110(2): 227-239.

2 Huang PL (2009) A comprehensive definition for metabolic syndrome. Dis Models Mech 2(6): 231-237.

3 IDF (2013) IDF definition of the metabolic syndrome: IDF, Available at http://www.idf.org/metabolic-syndrome/faqs.

4 Friend A, Craig L, Turner S (2013) The prevalence of metabolic syndrome in children: A systematic review of the literature. Metab Syndr Relat Disord 11(2): 71-80.

5 Chinali M, De Simone G, Roman MJ, Best LG, Lee ET, et al. (2008) Cardiac markers of pre-clinical disease in adolescents with the metabolic syndrome: The strong heart study. J Am Coll Cardiol 52(11): 932-938.

6 Caprio S (2002) Insulin resistance in childhood obesity. J Pediatr Endocrinol Metab 15 Suppl 1: 487-492.

7 Kostovski M, Simeonovski V, Mironska K, Tasic V, Gucev Z (2018) Metabolic profiles in obese children and adolescents with insulin resistance. Open Access Maced J Med Sci 6(3): 511-518.

8 Berenson GS, Srinivasan SR, Bao W, Newman WP, Tracy RE, et al. (1998) Association between multiple cardiovascular risk factors and atherosclerosis in children and young adults: The Bogalusa heart study. N Engl J Med 338(23): 1650-1656.

9 Al Sabbah H, Vereecken CA, Elgar FJ, Nansel T, Aasvee K, et al. (2009) Body weight dissatisfaction and communication with parents among adolescents in 24 countries: International cross-sectional survey. BMC public health 9: 52 .

10 Abdeen Z, Jildeh C, Dkeideek S, Qasrawi R, Ghannam I, et al. (2012) Overweight and obesity among palestinian adults: Analyses of the anthropometric data from the first national health and nutrition survey (1999-2000). J Obes pp: 213-547.

11 Damiri B, Abualsoud MS, Samara AM, Salameh SK (2018) Metabolic syndrome among overweight and obese adults in Palestinian refugee camps. Diabetol Metab Syndr 10: 34.

12 Abdul-Rahim HF, Husseini A, Bjertness E, Giacaman R, Gordon NH, et al. (2001) The metabolic syndrome in the west bank population: An urban-rural comparison. Diabetes Care 24(2): 275-279.

13 Sirdah MM, Abu Ghali AS, Al Laham NA (2012) The reliability of the National Cholesterol Education Program's Adult Treatment Panel III (NCEP/ATP III) and the International Diabetes Federation (IDF) definitions in diagnosing metabolic syndrome (MetS) among Gaza Strip Palestinians. Diabetol Metab Syndr 6(1): 4-8.

14 Sirdah MM, Al Laham NA, Abu Ghali AS (2011) Prevalence of metabolic syndrome and associated socioeconomic and demographic factors among Palestinian adults (20-65 years) at the Gaza Strip. Diabetol Metab Syndr 5(2): 93-97.

15 Damiri B, Aghbar A, Alkhdour S, Arafat Y (2017) Characterization and prevalence of metabolic syndrome among overweight and obese young Palestinian students at An-Najah National University. Diabetol Metab Syndr 30(17): 30424-30431.

16 Kassi E, Pervanidou P, Kaltsas G, Chrousos G (2011) Metabolic syndrome: Definitions and controversies. BMC Medicine 9: 48.

17 Cook S, Weitzman M, Auinger P, Nguyen M, Dietz WH (2013)
Prevalence of a metabolic syndrome phenotype in adolescents: Findings from the third national health and nutrition examination survey, 1988-1994. Arch Pediatr Adolesc Med 157(8): 821-827.

18 Cara JF, Chaiken RL (2006) Type 2 diabetes and the metabolic syndrome in children and adolescents. Curr Diab Rep 6(3): 241-250.

19 Zimmet P, Alberti G, Kaufman F, Tajima N, Silink M, et al. (2007) The metabolic syndrome in children and adolescents. Lancet (London, England) 369(9579): 2059-2061.

20 IDF (2007) IDF definition of metabolic syndrome in children and adolescents: International Diabetes Federation, Available at https:// www.idf.org/e-library/consensus-statements/61-idf-consensusdefinition-of-metabolic-syndrome-in-children-and-adolescents.

21 Zimmet P, Alberti KG, Kaufman F, Tajima N, Silink M, et al. (2007) The metabolic syndrome in children and adolescents - an IDF consensus report. Pediatr Diabetes 8(5): 299-306.

22 Alberti KG, Zimmet P, Shaw J (2006) Metabolic syndrome: A new world-wide definition. A consensus statement from the International Diabetes Federation. Diabet Med 23(5): 469-480.

23 Wan NJ, Mi J, Wang TY, Duan JL, Li M, et al. (2007) Metabolic syndrome in overweight and obese schoolchildren in Beijing. Chinese journal of paediatrics 45(6): 417-421.

24 Anderson PJ, Critchley JA, Chan JC, Cockram CS, Lee ZS, et al. (2001) Factor analysis of the metabolic syndrome: Obesity vs insulin resistance as the central abnormality. Int J Obes (Lond) 25(12): 17821788.

25 Alberti KG, Zimmet P, Shaw J (2006) Metabolic syndrome: A new world-wide definition. A Consensus Statement from the International Diabetes Federation. Diabet Med 23(5): 469-480.

26 NCEP TROTNCEP (2001) Executive summary of the third report of The National Cholesterol Education Program (NCEP) expert panel on detection, evaluation, and treatment of high blood cholesterol in adults (Adult Treatment Panel III). JAMA 285(19): 2486-2497.

27 Nesto RW (2003) The relation of insulin resistance syndromes to risk of cardiovascular disease. Rev Cardiovasc Med 4 Suppl 6: 11-18.

28 Bisschop CN, Peeters PH, Monninkhof EM, Van Der Schouw YT, May AM (2013) Associations of visceral fat, physical activity and muscle strength with the metabolic syndrome. Maturitas 76(2): 139-145.

29 Sachdev HP, Osmond C, Fall CH, Lakshmy R, Ramji S, et al. (2009) Predicting adult metabolic syndrome from childhood body mass index: Follow-up of the New Delhi birth cohort. Arch Dis Child 94(10): 768-774.

30 Obesity and Overweight (2013) http://www.who.int/mediacentre/ factsheets/fs311/en/index.html: WHO. Anthro Software.

31 Lawrence B, Rae-Chi H (2008) Childhood obesity, hypertension, the metabolic syndrome and adult cardiovascular disease. Clin Exp Pharmacol Physiol 35(4): 409-411.

32 Sarkar S, Das M, Mukhopadhyay B, Chakrabarti CS, Majumder PP (2006) High prevalence of metabolic syndrome and its correlates in two tribal populations of India and the impact of urbanization. Indian J Med Res 123(5): 679-686.

33 Dunstan DW, Zimmet PZ, Welborn TA, De Courten MP, Cameron AJ, et al. (2002) The rising prevalence of diabetes and impaired glucose tolerance: The Australian diabetes, obesity and lifestyle study. Diabetes Care 25(5): 829-834.

34 Schwandt P, Bertsch T, Haas GM (2010) Anthropometric screening 
for silent cardiovascular risk factors in adolescents: The PEP family heart study. Atherosclerosis 211(2): 667-671.

35 Cruz ML, Weigensberg MJ, Huang TT, Ball G, Shaibi GQ (2004) The metabolic syndrome in overweight Hispanic youth and the role of insulin sensitivity. J Clin Endocrinol Metab 89(1): 108-113.

36 Weiss R, Dziura J, Burgert TS, Tamborlane WV, Taksali SE, et al. (2004) Obesity and the metabolic syndrome in children and adolescents. $\mathrm{N}$ Engl J Med 350(23): 2362-274

37 Druet C, Dabbas M, Baltakse V, Payen C, Jouret B, et al. (2006) Insulin resistance and the metabolic syndrome in obese French children. $J$ Clin Endocrinol Metab 64(6): 672-678.

38 Eapen V, Mabrouk A, Yousef S (2010) Metabolic syndrome among the young obese in the United Arab Emirates. Ann Trop Paediatr 56(5): 325-328.

39 Mirhosseini NZ, Yusoff NA, Shahar S, Parizadeh SM, Mobarhen MG (2009) Prevalence of the metabolic syndrome and its influencing factors among adolescent girls in Mashhad, Iran. Asia Pac J Clin Nutr 18(1): 131-136

40 Jamoussi H, Mahjoub F, Sallemi H, Berriche O, Ounaissa K, et al. (2012) Metabolic syndrome in Tunisian obese children and adolescents. La Tunisie medicale 90(1): 36-40.

41 De Ferranti SD, Gauvreau K, Ludwig DS, Neufeld EJ, Newburger JW (2004) Prevalence of the metabolic syndrome in American adolescents: Findings from the third national health and nutrition examination survey. Circulation 110(16): 2494-2497.

42 Li Y, Yang X, Zhai F, Piao J, Zhao W, et al. (2008) Childhood obesity and its health consequence in China. Obes Rev 9 Suppl 1: 82-86.

43 Halley Castillo E, Borges G, Talavera JO, Orozco R, Vargas-Aleman, et al. (2007) Body mass index and the prevalence of metabolic syndrome among children and adolescents in two Mexican populations. J Adolesc Health 40(6): 521-526.

44 Sen Y, Kandemir N, Alikasifoglu A, Gonc N, Ozon A (2008) Prevalence and risk factors of metabolic syndrome in obese children and adolescents: The role of the severity of obesity. Eur J Pediatr 167(10): 1183-1189.
45 IDF (2013) IDF definition of metabolic syndrome in children and adolescents: IDF, Available at http://www.idf.org/metabolicsyndrome/children.

46 IDF (2006) The IDF consensus worldwide definition of the metabolic syndrome. The IDF consensus worldwide definition of the Internet, Available at https://www.idf.org/webdata/docs/MetS_def_ update2006.pdf.

47 Alberti KG, Zimmet PZ (1998) Definition, diagnosis and classification of diabetes mellitus and its complications. Part 1: Diagnosis and classification of diabetes mellitus provisional report of a WHO consultation. Diabet Med 15(7): 539-553.

48 Jessup A, Harrell JS (2005) The metabolic syndrome: Look for It in children and adolescents. Clin Diabete 23(1): 26.

49 Reaven GM (1988) Role of insulin resistance in human disease. Diabetes 37(12): 1595.

50 El Bilbeisi AH, Shab-Bidar S, Jackson D, Djafarian K (2017) The prevalence of metabolic syndrome and its related factors among adults in palestine: A meta-analysis. Ethiop J Health Sci 27(1): 77-84.

51 El Kishawi RR, Soo KL, Abed YA, Muda WA (2014) Obesity and overweight: Prevalence and associated socio demographic factors among mothers in three different areas in the Gaza Strip-Palestine: A cross-sectional study. BMC Obes 1(7): 2052-9538.

52 Abu Sham'a RA, Darwazah AK, Kufri FH, Yassin IH, Torok NI (2009) MetS and cardiovascular risk factors among Palestinians of East Jerusalem. East Mediterr Health J 15(6): 1464-1473.

53 Reinehr T, De Sousa G, Toschke AM, Andler W (2007) Comparison of metabolic syndrome prevalence using eight different definitions: A critical approach. Archives of disease in childhood 92(12): 1067-1072.

54 Kim S, So WY (2016) Prevalence of metabolic syndrome among Korean adolescents according to the national cholesterol education program, adult treatment panel $\mathrm{III}$ and international diabetes federation. Nutrients 8(10): 588.

55 Tavares Giannini D, Caetano Kuschnir MC, Szklo M (2014) Metabolic syndrome in overweight and obese adolescents: A comparison of two different diagnostic criteria. Ann Nutr Metab 64(1): 71-79. 